\title{
PComp-Model: desenvolvendo competências para o Pensamento Computacional
}

\author{
Maria Claudete Schorr, PPGIE, UFRGS, mclaudetesw@gmail.com \\ Magda Bercht, PPGIE, UFRGS, bercht@inf.ufrgs.br
}

Resumo. Este artigo apresenta um modelo de Ensino e Aprendizagem intitulado PComModel que tem por objetivo desenvolver competências para o Pensamento Computacional. Uma instância do modelo está estruturada em duas versões, uma para o aluno e outra para o professor, o modelo baseia-se na arquitetura de manipulação de dados definida por: Entrada, Processamento e Saída de dados. Em um estudo com estudantes do $3^{\circ}$ ano do Ensino Médio no componente curricular de Biologia, o modelo apresentou resultados positivos no que se refere à interpretação e ao nível de abstração durante a elaboração das soluções para os problemas propostos.

Palavras-chave: Pensamento Computacional. Ensino. Aprendizagem. Competências.

\section{Pcomp-Model: developing skills for Computational Thinking}

\begin{abstract}
This paper presents a model of Teaching and Learning entitled PCompModel that aims to develop competencies for Computational Thinking. An instance of the model is structured in two versions, one of them for the student and another for the teacher, the model is based on the data manipulation architecture defined as: Input, Processing and Output of data. A study has been performed wtih students in 3rd year of high school in the discipline of Biology. The results presented with the model were positives regarding the interpretation and level of abstraction of the students in solving proposed problems.
\end{abstract}

Keywords: Computational Thinking. Teaching. Learning. Skills.

\section{Introdução}

Ensinar neste novo século se tornou um grande desafio para os educadores. Os estudantes estão munidos de recursos tecnológicos, com acesso a milhares de informações em um curto espaço de tempo, sem saberem muitas vezes como lidar com isso ou como fazer uso destes recursos para a sua aprendizagem (VALENTE, 2019; MALHEIROS, 2019). Além da rapidez no acesso às informações, estes requerem respostas em um curto espaço de tempo, ou melhor, de imediato, prejudicando o processo de abstração e consequentemente a interpretação.

É possível perceber que estes estudantes não detém o tempo necessário para fazer a abstração de um dado enunciado, como consequência, suas soluções acabam sendo prejudicadas. O professor possui a responsabilidade de encontrar meios que auxiliam o estudante em sua aprendizagem. As Metodologias Ativas (MA) representam uma alternativa para promover o estudante como protagonista do seu processo de aprendizagem, passando o professor a atuar como orientador (MALHEIROS, 2019). Porém, isso não é suficiente, principalmente quando se trata de problemas complexos, logo a inserção de outros meios, técnicas ou recursos além das MA são necessários para desenvolver no estudante a capacidade de resolver problemas de maneira autônoma. 
Wing (2006) e Valente (2019) definem que desenvolver o Pensamento Computacional (PC) significa desenvolver habilidades como abstração, raciocínio lógico, reconhecimento de padrões, interpretação, sequenciamento, entre outras. Ainda segundo os autores, o PC permite auxiliar na resolução de problemas. Brackmann (2017) e Boucinha (2015) também apoiam esta ideia, sugerindo atividades plugadas ${ }^{1}$ com a utilização do software Scratch, além de atividades desplugadas ${ }^{2}$.

Piaget (1978) definiu que processo de construção do conhecimento se dá por meio do Fazer ao Compreender. Em 1980, Papert preocupado com o processo cognitivo das crianças, desenvolveu suas pesquisas no Massachusetts Institute of Technology (MIT), utilizando a linguagem de programação Logo com base em estudos piagetianos. A ferramenta Scratch, criada em 2007 no MIT, vai ao encontro dessa filosofia exposta por Piaget, justamente por ser uma ferramenta educativa de fácil interação, com ambiente gráfico e intuitivo, atualmente adotada por muitas instituições de ensino desde as séries iniciais.

Assim como o Logo e Scratch existem outras ferramentas tecnológicas disponíveis no mercado, porém apenas o uso delas não é o suficiente para de fato desenvolver as habilidades do PC. Os estudantes continuam apresentando problemas de interpretação e abstração durante a resolução de problemas. Com base nessas dificuldades, o modelo PComp-Model, apresentado nesse artigo, foi concebido no intuito de auxiliar o estudante a organizar suas estratégias de resolução de problemas, assim como, apoiar o professor na criação de atividades que estimulem o PC.

Neste artigo são apresentados na seção 2 e 3 bases que subsidiaram bibliograficamente a concepção do modelo. Na seção 4 ocorre a especificação do modelo PComp-Model, organizado em duas seções: aluno e professor. Por último, nas seções 5 e 6, respectivamente, são apresentadas a validação do modelo junto a uma turma de Educação Básica e as Considerações Finais.

\section{Competências: Conhecimento, Habilidades e Atitudes}

Behar (2013) e Perrenoud (1999) afirmam que ter competência significa ter Conhecimentos, Habilidades e Atitudes (CHA) sobre um determinado assunto. Nesta vertente ser competente significa possuir capacidade de "saber = ter conhecimento", "saber fazer = ter habilidade" e "saber ser $=$ ter atitude", elementos estes que compõem a competência (CHA), segundo Behar (2013, p. 26).

Para Perrenoud $(1999$, p.18) conhecimento é o elemento que corresponde ao saber do sujeito em relação a uma determinada competência.

Para mim, saberes e conhecimentos são representações organizadas do real, que utilizam conceitos ou imagens mentais para descrever e, eventualmente, explicar, às vezes antecipar ou controlar, de maneira mais ou menos formalizada e estruturada, fenômenos, estados, processos, mecanismos observados na realidade ou inferidos a partir da observação.

A habilidade, segundo Behar (2013, p. 28) é "[..] uma ação automatizada, um procedimento já construído, algo da ordem do operacional, não exigindo se deter em uma reflexão mais aprofundada. Refere-se ao colocar em prática, em saber fazer". Ainda segundo a autora p. 29, “[...] as habilidades são de caráter essencialmente prático, técnico e procedimental". Atitude segundo Behar (2013) refere-se ao posicionamento do sujeito no enfrentamento dos problemas propostos ou situações do cotidiano. Atitude

1 Atividades Plugadas $\rightarrow$ são atividades realizadas com a utilização de recursos tecnológicos.

2 Atividades Desplugadas $\rightarrow$ atividades sem a utilização de hardware e software.

V. $18 \mathrm{~N}^{\mathrm{o}} 1$, julho, 2020

DOI: 
envolve o lado social e cultural do indivíduo frente ao seu comportamento durante a resolução de problemas.

O PComp-Model está apoiado neste conceito de competência apresentado por Behar (2013) e Perrenoud (1999), propondo por meio de um roteiro guiado, ser possível desenvolver conhecimento, habilidade e atitude, durante o processo de resolução problemas.

\section{Pensamento Computacional (PC)}

O termo PC foi criado por Jeannette Maria Wing em sua primeira publicação sobre o tema, intitulado Computational Thinking em 2006. Pensamento Computacional é uma abordagem para a resolução de problemas que utiliza conceitos como: abstração, raciocínio lógico, sequenciamento, reconhecimento de padrões, algoritmos, decomposição, entre outros (WING, 2006; BRACKMANN (2017); BOUCINHA (2017); POLONI e WEBBER (2019).

Conforme Wing (2017), para o desenvolvimento do PC, a habilidade de abstração é fundamental. Abstração segundo Dicio (texto digital) é a "ação de abstrair, de analisar isoladamente um aspecto, contido num todo, sem ter em consideração sua relação com a realidade". Para Piaget (1995) a abstração pode ser dividida em três níveis, sendo eles: a abstração propriamente dita, consistindo em separar formas de organização dos conhecimentos do sujeito; o reflexionamento, que permite elaborar um projeto do que foi abstraído; reflexão é o ato de reconstruir mentalmente um novo plano.

O ato de abstrair é fundamental para a interpretação de um enunciado de um problema, exercício ou mesmo atividade. A partir da abstração o sujeito faz o reconhecimento de padrões, elabora uma sequencia lógica para a solução. Neste sentido, utilizar mecanismos que auxiliam no desenvolvimento da abstração, interpretação e elaboração da solução são fundamentais em qualquer nível de ensino. Ao praticar esses conceitos desde a Educação Básica (EB) o estudante ingressa no Ensino Superior (ES) com a competência de resolução de problemas já desenvolvida, possibilitando o sucesso do estudante nos componentes curriculares que necessitam desta competência.

O PC segundo Brackmann et al. (2019) é composto por quatro pilares necessários para a resolução de problemas, sendo eles: Decomposição, Reconhecimento de Padrões, Abstração e Algoritmos. O pilar Decomposição significa quebrar um problema complexo em pedaços menores de forma que cada pedaço possa ser solucionado individualmente por meio de reconhecimento de problemas já resolvidos anteriormente. Durante a resolução do problema, identificar os pontos importantes do problema e ignorar aqueles que não são necessários para a resolução, está vinculado ao pilar Abstração. A descrição dos passos de forma detalhada e com uma sequência lógica é o último passo, pilar definido como Algoritmo.

\section{Materiais e Métodos}

Esta pesquisa caracteriza-se de caráter experimental com análise qualitativa. A fase experimental efetivou-se por meio da criação do modelo PComp-Model dividido em seis etapas, sendo cinco delas destinadas para realização de experimentos, coleta e análise informações, para então, na sexta etapa, conceber o modelo em duas seções: aluno e professor. Uma validação do modelo, com análise qualitativa, foi realizada com alunos do $3^{\circ}$ ano do Ensino Médio na disciplina de Biologia. O levantamento dos dados qualitativos Os passos para concepção do modelo e o modelo propriamente dito, são 
apresentados neste capítulo. A validação junto a turma de Biologia é apresentada no Capítulo 5.

\section{1 - Etapas de concepção do modelo PComp-Model}

\section{Etapa 1 - Análise do desempenho dos estudantes na disciplina de Algoritmos e Programação e no EM}

Foram analisados os históricos escolares do Ensino Médio de 137 estudantes que cursaram o componente curricular de Algoritmos e Programação, nos semestres 2016A, 2016B e 2017A, de uma Instituição de Ensino Superior. Durante esta análise identificou-se que os estudantes com melhores desempenhos correspondiam àqueles que tinham um bom desempenho nos componentes curriculares de Matemática, Física e Português no Ensino Médio (SCHORR e BERCHT, 2018).

\section{Etapa 2 - Resolução de problemas parte 1}

Nesta etapa foram aplicadas 10 questões (problemas do tipo Algoritmos) com estudantes da Graduação, no componente curricular de Algoritmos e Programação com o objetivo de avaliar a capacidade de resolução de problemas, abstração e raciocínio lógico. Participaram 24 estudantes. Durante a aplicação do experimento, três estudantes utilizaram a técnica think aloud, que segundo Fonteyn et al. (1993) significa pensar em voz alta durante a resolução de uma tarefa, sendo muito importante para capturar a ação realizada e o pensamento do usuário de forma sincronizada. Em análise quantitativa dos exercícios, $43 \%$ dos estudantes acertaram todas as questões, os demais erraram de 1 a 3 questões. $\mathrm{O}$ resultado foi satisfatório, porém ao analisar a narração dos três estudantes notou-se que nas questões objetivas foi utilizado o processo de eliminação até chegar à resposta. Com base nisso um novo experimento foi realizado.

\section{Etapa 3 - Resolução de problemas parte 2}

Não obtendo resultados significativos na etapa 2 aplicou-se questões muito semelhantes, porém desta vez questões de caráter subjetivo. Com o intuito de melhor análise das respostas, no que tange o nível de abstração do aluno, foram requeridas respostas com detalhamento dos passos, de maneira discursiva. Confirmou-se a hipótese "estudantes possuem dificuldades na abstração e interpretação o que interfere na resolução do problema".

\section{Etapa 4 - Mapeamento das etapas necessárias para a resolução de problemas}

Com base na resolução detalhada dos problemas das etapas 2 e 3, mapeou-se as etapas necessárias para a resolução de problemas (Quadro1). Notou-se que a maior dificuldade está nas etapas 3 - abstração e 5 - tradução para codificação, em destaque.

\begin{tabular}{|c|l|l|}
\hline 1 & Problema & \multicolumn{1}{|c|}{ Descrição do problema } \\
\hline 2 & Interpretação & Entendimento/Compreensão \\
\hline 3 & Abstração & Seleção dos elementos-chave \\
\hline 4 & Linguagem natural & Narrativa macro da solução = sequenciamento lógico \\
\hline 5 & $\begin{array}{l}\text { Tradução para } \\
\text { codificação }\end{array}$ & $\begin{array}{l}\text { Transposição da solução em nível detalhado (estruturas de como resolver } \\
\text { especificamente) }\end{array}$ \\
\hline 6 & Codificação & Código-fonte, modelo, cálculo, texto \\
\hline 7 & Problema resolvido & Solução implementada \\
\hline
\end{tabular}




\section{Etapa 5 - Mapeamento das competências para o desenvolvimento do PC}

O modelo PComp-Model utiliza como premissa base as competências apresentadas no Quadro 2, fundamentais para desenvolvimento do PC. O mapeamento se deu a partir de um estudo exploratório sobre trabalhos correlatos de Henrique e Tedesco (2017) e Silva et al. (2015), além da análise das competências propostas na Base Nacional Comum Curricular (BNCC) para o Ensino Médio, no que se refere aos componentes curriculares de Matemática, Física e Português, conforme resultados verificados nas etapas 2 e 3 deste estudo.

\begin{tabular}{|l|l|l|}
\hline Competências & \multicolumn{2}{|l|}{ Conhecimentos, Habilidades e Atitudes - CHA } \\
\hline Computação & C & Saber usar desvios condicionais, repetições, sequência lógica \\
\cline { 2 - 3 } & H & $\begin{array}{l}\text { Resolver problemas complexos utilizando os conceitos da computação. } \\
\text { Avaliação de vantagens e desvantagens de diferentes algoritmos. Utilização de } \\
\text { classes, métodos, funções e parâmetros para dividir e resolver problemas. (BNCC, } \\
\text { 2018) }\end{array}$ \\
\cline { 2 - 4 } & A & $\begin{array}{l}\text { Ter autonomia, motivação e autoconfiança para resolver problemas utilizando } \\
\text { linguagens de programação. }\end{array}$ \\
\hline $\begin{array}{l}\text { Resolução de } \\
\text { Problemas }\end{array}$ & C & Matemática básica, leitura e interpretação de textos \\
\cline { 2 - 3 } & H & $\begin{array}{l}\text { Abstração, decomposição, reconhecimento de padrões, algoritmos, raciocínio } \\
\text { lógico, sequenciamento. Compreensão e escrita de algoritmos. }\end{array}$ \\
\cline { 2 - 3 } & A & Ter autonomia, motivação e autoconfiança para resolver problemas. \\
\hline & Quadro 2: Competências mapeadas fundamentais para desenvolver o PC \\
\hline
\end{tabular}

\section{Etapa 6 - Elaboração do modelo de ensino e aprendizagem PComp-Model}

Tomando como subsídio as informações e análises das etapas de um a cinco, foi elaborado o modelo de ensino e aprendizagem organizado em duas seções: professor e aluno. As seções estão divididas em blocos. Na seção professor a estrutura está dividida em cinco blocos, permitindo ao professor, ao final, criar enunciados de exercícios, com base em perguntas estruturadas em cada bloco.

A seção aluno, composta por quatro blocos, visa apoiar o estudante na resolução dos exercícios. De maneira idêntica, perguntas devem ser respondidas pelo aluno em cada bloco do modelo. A quantidade e tipo de perguntas em cada bloco foram criadas objetivando promover o desenvolvimento do Pensamento Computacional, com foco na abstração. A cada pergunta, tanto para o professor quanto para o aluno, dicas sobre o preenchimento são disponibilizadas durante todo o percurso.

Comum às duas seções do modelo está à segmentação em blocos organizados em Entrada, Saída e Processamento, nessa ordem. Essa estrutura promove o pensamento crítico e sistematizado a respeito de problemas genéricos, assumindo que para um dado problema, deve haver sua compreensão, para a partir dela, extrair: as entradas responsáveis por fornecer subsídios ao processo de resolução; as saídas: correspondentes aos materiais, produtos ou artefatos gerados a partir da solução; e o processamento: onde ocorrerá a resolução do problema. A lógica do modelo está estruturada em obter compreensão sobre as entradas identificadas e as saídas esperadas, para então elaborar uma estratégia de como resolver o problema.

\section{2 - Modelo PComp-Model - Seção Aluno}

A seção Aluno (Quadro 3) permite resolver os exercícios criados na seção Professor. Além dos blocos de Entrada, Saída e Processamento mencionados, o bloco inicial da seção Aluno estimula o pensar do problema com base na identificação dos principais V. $18 \mathrm{~N}^{\mathrm{o}} 1$, julho, 2020 RENOTE DOI: 
verbos, palavras-chave, personagens, objetos e ações. Essa reflexão desperta a visão sobre o todo, extraindo elementos importantes para compreensão do problema.

\begin{tabular}{|c|c|c|c|}
\hline \multicolumn{4}{|c|}{ Modelo para apoio na resolução de problemas com base no desenvolvimento do PC } \\
\hline \multicolumn{4}{|c|}{$\begin{array}{l}\text { Palavras-chave: neste bloco o estudante será guiado a identificar os principais verbos, personagens, objetos, ações e palavras } \\
\text { importantes do enunciado. }\end{array}$} \\
\hline & Questão & \multicolumn{2}{|r|}{ Dica/explicação } \\
\hline 2 & $\begin{array}{l}\text { Destaque as principais ações/verbos do } \\
\text { problema? }\end{array}$ & \multicolumn{2}{|r|}{$\begin{array}{l}\text { Dica: leve em consideração aquilo que deverá ser feito para conseguir resolver } \\
\text { o problema. São verbos que definem ações cruciais do problema, como por } \\
\text { exemplo: calcular, identificar, analisar, comparar, descrever, testar e } \\
\text { implementar. Esses verbos estarão ligados diretamente com as ações } \\
\text { desempenhadas pelos atores do problema, quando existirem. }\end{array}$} \\
\hline 3 & Elenque as demais palavras do problema? & \multicolumn{2}{|r|}{$\begin{array}{l}\text { Dica: além dos verbos, identifique substantivos e adjetivos que colaboram } \\
\text { para a compreensão do que está sendo manipulado no problema. Ex.: } \\
\text { alto/baixo, caro/barato, frutas, roupas, lugares. Essas palavras estão } \\
\text { diretamente ligadas à cena principal do problema. }\end{array}$} \\
\hline 4 & $\begin{array}{l}\text { Diga quais são os personagens envolvidos } \\
\text { no problema? }\end{array}$ & \multicolumn{2}{|r|}{ Dica: personagens podem ser pessoas ou animais } \\
\hline 6 & Quais são as ações dos personagens? & \multicolumn{2}{|r|}{$\begin{array}{l}\text { Dica: não é por coincidência, mas as ações dos personagens estão alinhadas } \\
\text { com os verbos-chave do problema. Caso alguma ação de personagem seja } \\
\text { identificada aqui e não conste como um verbo-chave do problema, revise } \\
\text { ambos os itens e busque estabelecer alinhamento. }\end{array}$} \\
\hline \multicolumn{4}{|r|}{ Entrada de Dados } \\
\hline \multicolumn{4}{|c|}{$\begin{array}{l}\text { O objetivo dessa seção é mapear quais informações são necessárias para resolver o problema. Essas informações podem estar no } \\
\text { enunciado ou nos materiais de apoio, ou estarem ocultas, exigindo que resgate essa informação em conhecimentos anteriormente } \\
\text { adquiridos ou busque por meio de pesquisa. } \\
\text { Dica para o aluno: As entradas de um problema são como a matéria-prima para confecção de um produto. É importante identificar o } \\
\text { que foi fornecido e o que está faltando para que consigamos resolver o problema. Informações faltantes devem ser adquiridas. }\end{array}$} \\
\hline 7 & \multicolumn{2}{|c|}{\begin{tabular}{l|l} 
Quais são os tipos/categorias de informação & I \\
fornecidas para resolução do problema? & f \\
Exemplos: Equações/fórmula, Números, Solução & \\
detalhada passo a passo, Desenho, Figura, Mapa, \\
Vídeo, Áudio, Resumo, Redação, Relatório, \\
Resenha, Parágrafo. Outro?
\end{tabular}} & $\begin{array}{lcccc}\text { Dica: aplicam-se a esse contexto: } & \text { textos, } & \text { números } \\
\text { figuras/diagramas/gráficos, fórmulas, vídeo, áudio. } & & \end{array}$ \\
\hline 9 & \multicolumn{2}{|l|}{$\begin{array}{l}\text { Quais são as informações NÃO fornecidas } \\
\text { explicitamente no enunciado do exercício que } \\
\text { servem como subsídio para resolver o problema? }\end{array}$} & $\begin{array}{l}\text { ca: pense em informações que deveriam ser consideradas para } \\
\text { aseguir resolver o problema, no entanto, as mesmas não são fornecidas } \\
\text { enunciado. Ex.: Para um cálculo da área da Física, a gravidade pode } \\
\text { ser informada explicitamente, mas sabe-se que há um valor }(9,8) \\
\text { drão para esse parâmetro a ser utilizado nos problemas desse tipo. Da } \\
\text { sma forma, para resolver um problema financeiro pode ser necessário } \\
\text { em mãos as cotações de moedas como dólar/euro, que não foram } \\
\text { necidas. }\end{array}$ \\
\hline \multicolumn{4}{|c|}{ Saída de Dados } \\
\hline \multicolumn{4}{|c|}{$\begin{array}{l}\text { O objetivo dessa seção é ter clareza sobre quais os resultados esperados do problema. } \\
\text { Dica para o aluno: Leve em consideração que um problema pode exigir múltiplas saídas sejam elas numéricas + textuais, figuras }+ \\
\text { textuais + numéricas, dentre outras possíveis combinações. }\end{array}$} \\
\hline 10 & \multicolumn{2}{|l|}{$\begin{array}{l}\text { Em que formato será apresentado o resultado? } \\
\text { Exemplos: Equações/fórmula, Números, Solução } \\
\text { detalhada passo a passo, Desenho, Figura, Mapa, } \\
\text { Vídeo, Áudio, Resumo, Redação, Relatório, } \\
\text { Resenha, Parágrafo. Outro? }\end{array}$} & $\begin{array}{l}\text { Dica: com base em fórmulas (fornecida explicitamente ou implicitamente) } \\
\text { obtém-se o resultado para o problema representado por meio de números, } \\
\text { equações ou expressões. }\end{array}$ \\
\hline \multicolumn{4}{|c|}{ Processamento de Dados } \\
\hline \multicolumn{4}{|c|}{ O objetivo dessa seção é determinar quais os possíveis meios para resolver o problema. } \\
\hline 11 & \multicolumn{2}{|c|}{$\begin{array}{l}\text { Para resolver o problema você precisa utilizar } \\
\text { cálculos? Quais? }\end{array}$} & $\begin{array}{l}\text { Dica: tenha em mente que fórmulas/regras podem ser necessárias } \\
\text { para resolver o problema. }\end{array}$ \\
\hline
\end{tabular}

V. $18 \mathrm{~N}^{\circ} 1$, julho, 2020

DOI: 
Calculadora, Outros? Nenhum.

14 Para resolver o problema, é necessário realizar algum experimento? Quais?

15 Solução

Dica: uma experimentação pode envolver: medições, testes/avaliações com determinados elementos ou pessoas, confecção de algum aparato/objeto, validações de hipóteses.

Dica: escreva ou envie o arquivo contendo a solução do problema.

Quadro 3: PComp-Model - seção Aluno

\section{3 - Modelo PComp-Model - Seção Professor}

A seção Professor (Quadro 4) visa auxiliar o professor na criação de novos exercícios, auxiliando-o da mesma forma como ao aluno, oferecendo questionamentos e dicas, em uma sequência lógica dentro dos blocos. Os professores, de igual maneira aos alunos, têm a dificuldade de visualizar os problemas de maneira estruturada. Assim sendo, essa seção busca estimular o pensamento crítico e estruturado no lado professor, enquanto proponente de atividades.

De forma similar, a seção Professor possui blocos específicos, pertinentes à criação de atividades. Dois blocos iniciais buscam detalhar elementos como: Componente curricular, Assunto, Conhecimentos desejáveis a atingir, Habilidades da BNCC e do PC, e Atitudes necessárias para resolução do problema.

\begin{tabular}{|c|c|c|c|c|}
\hline \multicolumn{5}{|c|}{$\begin{array}{l}\text { PComp-Model: Modelo para elaboração de enunciados de ex } \\
\text { relacionadas a programação e resolução de problemas. }\end{array}$} \\
\hline & Questão & \multicolumn{3}{|c|}{ Explicação } \\
\hline 1 & Componente Curricular & \multicolumn{3}{|c|}{ O professor deverá assinalar o nome do componente curricular para o qual será criado o enunciado } \\
\hline 2 & Assunto & \multicolumn{3}{|c|}{ Informe aqui o assunto/conteúdo que será trabalhado na atividade } \\
\hline 3 & $\begin{array}{l}\text { Escreva o enunciado } \\
\text { provisório do problema. }\end{array}$ & \multicolumn{3}{|c|}{$\begin{array}{l}\text { Neste item o professor deve escrever o enunciado do exercício de forma provisória, ao final ele } \\
\text { poderá ser ajustado. }\end{array}$} \\
\hline \multicolumn{5}{|c|}{ Quanto aos Conhecimentos, Habilidades e Atitudes: } \\
\hline 4 & \multicolumn{2}{|c|}{ Quais são os conhecimentos que se espera atingir? } & \multicolumn{2}{|r|}{$\begin{array}{l}\text { Devem ser informados os conhecimentos que o aluno deverá adquirir } \\
\text { por meio do exercício proposto. }\end{array}$} \\
\hline 5 & \multicolumn{2}{|c|}{$\begin{array}{l}\text { Quais habilidades relacionadas ao assunto devem } \\
\text { ser desenvolvidas? }\end{array}$} & \multicolumn{2}{|r|}{$\begin{array}{l}\text { Relação das habilidades que devem ser desenvolvidas pelo aluno } \\
\text { durante a resolução exercício de acordo com a BNCC. }\end{array}$} \\
\hline 6 & \multicolumn{2}{|c|}{$\begin{array}{l}\text { Quais habilidades do Pensamento Computacional } \\
\text { devem ser desenvolvidas durante a resolução do } \\
\text { problema proposto? }\end{array}$} & \multicolumn{2}{|r|}{$\begin{array}{l}\text { Nesta questão serão listadas as habilidades do PC para o professor } \\
\text { marcar aquelas que serão desenvolvidas. Para cada uma terá uma } \\
\text { breve explicação de seu significado. }\end{array}$} \\
\hline 7 & \multicolumn{2}{|c|}{$\begin{array}{l}\text { Quais são as atitudes necessárias para resolução do } \\
\text { problema? }\end{array}$} & \multicolumn{2}{|r|}{$\begin{array}{l}\text { Relação de atitudes será disponibilizada, o professor apenas seleciona } \\
\text { as que serão necessárias para a resolução do problema. }\end{array}$} \\
\hline \multicolumn{5}{|c|}{ Entrada de Dados - Pontos Chave do Problema/Exercício } \\
\hline 8 & \multicolumn{3}{|c|}{$\begin{array}{l}\text { Quais são os principais verbos/ações que devem ser } \\
\text { seguidas para resolver o exercício? } \\
\text { Será fornecida uma lista de opções. }\end{array}$} & $\begin{array}{l}\text { Nesta questão o professor deverá relacionar os verbos que } \\
\text { fazem parte do enunciado, o objetivo desta questão é definir as } \\
\text { ações do exercício. }\end{array}$ \\
\hline 9 & \multicolumn{3}{|c|}{$\begin{array}{l}\text { Quais são as demais palavras chave do enunciado que } \\
\text { auxiliam na resolução do problema? }\end{array}$} & $\begin{array}{l}\text { Nesta questão as palavras chave devem ser substantivos, } \\
\text { adjetivos, palavras chave para a compreensão do problema. }\end{array}$ \\
\hline 10 & \multicolumn{3}{|c|}{$\begin{array}{l}\text { Quais personagens mencionados no enunciado estão } \\
\text { envolvidos? Se você não pensou em personagem, pense } \\
\text { agora e defina algum. }\end{array}$} & $\begin{array}{l}\text { ersonagem para facilitar } \\
\text { ser realizadas. }\end{array}$ \\
\hline 11 & \multicolumn{3}{|c|}{$\begin{array}{l}\text { Quais são os dados presentes no enunciado que serão } \\
\text { manipulados durante a resolução? }\end{array}$} & $\begin{array}{l}\text { Os dados de } \\
\text { a encontrar }\end{array}$ \\
\hline \multicolumn{5}{|c|}{ Saída de Dados } \\
\hline \multirow{2}{*}{\multicolumn{5}{|c|}{\begin{tabular}{l|l|l|l}
\multicolumn{3}{l}{ O objetivo dessa seção é ter clareza sobre quais são os resultados esperados do problema. } \\
12 & $\begin{array}{l}\text { A resposta do problema deve ser repre- } \\
\text { sentada em forma de: }\end{array}$ & $\begin{array}{l}\text { Nesta questão o professor deverá marcar como deseja que o aluno apresente a } \\
\text { resposta ou preencher caso não tiver a opção desejada. }\end{array}$
\end{tabular}}} \\
\hline & & & & \\
\hline \multicolumn{5}{|c|}{ Processamento } \\
\hline \multirow{2}{*}{\multicolumn{5}{|c|}{\begin{tabular}{|l|l|l|}
\multicolumn{3}{|c|}{ O objetivo dessa seção é determinar quais os possíveis meios para resolver o problema. } \\
13 & Para resolver o problema são necessários: & $\begin{array}{l}\text { Nesta questão o professor deverá indicar algum recurso que o aluno } \\
\text { possa utilizar para chegar à resposta. }\end{array}$
\end{tabular}}} \\
\hline & & & & \\
\hline 14 & \multicolumn{2}{|c|}{$\begin{array}{l}\text { Quais aparatos tecnológicos podem ser utilizados } \\
\text { para resolver o problema? }\end{array}$} & \multicolumn{2}{|r|}{$\begin{array}{l}\text { O professor nesta questão deverá indicar alguma ferramenta ou } \\
\text { aparato que poderá ser utilizado pelo aluno. }\end{array}$} \\
\hline 15 & \multicolumn{2}{|c|}{$\begin{array}{l}\text { Algum software/app/navegador/site você recomen- } \\
\text { da? Qual? }\end{array}$} & \multicolumn{2}{|r|}{$\begin{array}{l}\text { Nesta questão o professor poderá sugerir ferramentas computacionais } \\
\text { que poderão ser utilizadas para resolver o problema. }\end{array}$} \\
\hline
\end{tabular}

Quadro 4: PComp-Model - seção Professor

DOI: 
As duas seções do modelo atuam, tanto de forma complementar, como de forma isolada. Alunos que utilizarem o modelo para resolver problemas, serão estimulados e guiados por uma série de reflexões, que tendem a tornar-se automáticas com o passar do tempo devido à sua repetição. Quando exercícios e respostas forem elaborados com base no modelo, é possível confrontar o esperado e pensado pelo professor, com o produto final entregue pelo aluno, possibilitando análise do resultado e da metodologia de desenvolvimento empregado na atividade.

\section{Validação do Modelo}

O modelo PComp-Model foi validado com um grupo de alunos de $3^{\circ}$ ano do Ensino Médio, composto por oito participantes. O componente curricular utilizado no experimento foi Biologia, escolhido ao acaso, uma vez que o modelo foi pensado para ser utilizado em qualquer componente curricular. A ferramenta Google Forms serviu como instrumento para elaboração das questões por parte do professor, como também coleta de respostas dos alunos.

A validação foi organizada em cinco etapas, sendo elas:

Etapa 1: Treinamento para o professor referente a utilização do modelo. Neste momento foi apresentado para o professor o modelo, o objetivo do mesmo, as questões que o compõe, além de como utilizá-lo. Esta etapa foi realizada em 3 horas.

Etapa 2: Ajustes no modelo. Após apresentação do modelo para o professor, mudanças foram percebidas e então ajustadas, obtendo uma nova versão do modelo, apresentado nesse artigo. Algumas questões do modelo foram percebidas com um nível muito alto de dificuldade por parte do professor, neste sentido estas foram reformuladas.

Etapa 3: Elaboração de exercícios pelo professor. De posse da nova versão do modelo, o professor elaborou enunciados de alguns exercícios. O professor mencionou melhora na versão do modelo, quanto à clareza e simplicidade. Essa atividade durou 3 horas.

Etapa 4: Resolução do exercício pelos alunos utilizando o modelo. Foram agendados dois períodos de 50 min para a resolução dos exercícios. Inicialmente foi apresentado o modelo para os alunos, depois com a utilização do celular eles passaram a responder as questões. Os alunos se mostraram motivados enquanto respondiam as questões, nas dúvidas muitas vezes discutiam com os colegas, não apresentaram dificuldades na utilização do modelo.

Etapa 5: Questionário de Satisfação. Dos oito estudantes que participaram, um não respondeu o questionário de satisfação, pois ausentou-se da aula mais cedo. Este questionário foi aplicado para identificar o que os estudantes sentiram ao utilizar o modelo. O Quadro 5 apresenta algumas respostas dos estudantes, ipsis litteris.

\begin{tabular}{|l|l|}
\hline Questão & Respostas \\
\hline O uso do Modelo & Sim, pois através do mesmo há informações e pôde-se ter acesso às mesmas \\
auxiliou na resolução do & Sim, por que sem ele não teria informação \\
problema proposto? Por & Mais ou menos, seria mais produtivo utilizar mais imagens e diagramas na explicação \\
que? & do problema \\
& Sim, pois ajudou a ter raciocínio lógico \\
& Sim, ajudou a retirar informações úteis para elaborar uma resposta mais completa \\
& Sim, pois o texto foi como um texto de apoio \\
& Me auxiliou no processo de busca e coleta de dados \\
\hline
\end{tabular}




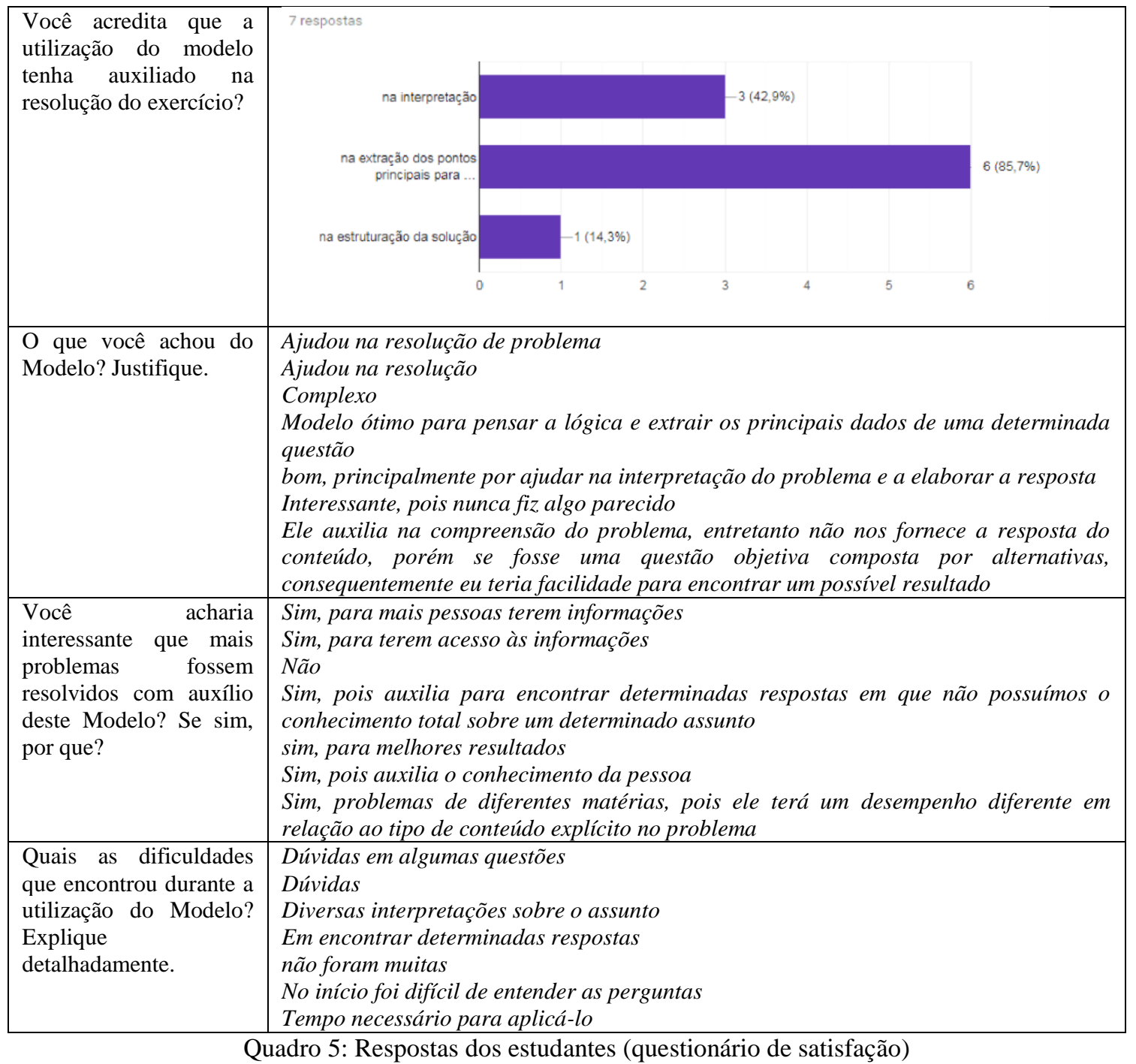

As respostas do questionário de satisfação demonstram que o modelo melhorou a compreensão do problema e da concepção da solução de maneira geral. Os alunos relataram positivamente, itens como: maior organização das ideias; estímulo ao raciocínio lógico; aplicação em outras matérias; e facilidade de identificação das informações necessárias. Como aspectos negativos, foram comentados: a falta de tempo para aplicar o modelo; dúvidas sobre algumas questões; e a complexidade do modelo. Quando questionados a respeito do auxílio fornecido para elaborar a solução do problema, $85,7 \%$ mencionaram que o modelo auxiliou na extração dos principais pontos, ou seja, identificar e compreender o que era necessário coletar para resolver o problema. A hipótese de "por meio do modelo o estudante constrói as competências que auxiliam na resolução de problemas" se confirma.

\section{Considerações finais}

O desenvolvimento do PC está sendo discutido no mundo todo, tendo em vista sua importância para a aprendizagem dos estudantes nas mais diferentes áreas do conhecimento (CSTA, 2017). Com base nisso foi desenvolvido o PComp-Model, servindo como instrumento de ensino e aprendizagem. A estrutura do modelo busca organizar os pensamentos de alunos e professores durante a execução de seus papéis, resolvendo problemas ou criando atividades, respectivamente.

V. $18 \mathrm{~N}^{\circ} 1$, julho, 2020 RENOTE DOI: 
A intervenção aqui apresentada, demonstra a importância e a aplicabilidade do modelo. $\mathrm{O}$ aluno mostrou-se mais motivado e o instigado a obter informações para resolver o problema. O professor, da mesma forma, produziu uma atividade mais encorpada, com maior nível de detalhamento, fato percebido em decorrência do processo de construção, que estimulou o pensar mais elaborado e organizado.

O modelo possui um diferencial diante de metodologias, softwares e recursos atualmente empregados por atuar no desenvolvimento das competências de abstração e interpretação. Entende-se que esta seja uma grande contribuição para minimizar a dificuldade dos estudantes na resolução de problemas. O PComp-Model conforme mencionado, pode ser utilizado em qualquer componente curricular, mantendo foco nas competências de resolução de problemas e computação para desenvolver no aluno o PC e as competências da área ou componente curricular específicos.

Após teste utilizando o Google Forms, de posse da prova de conceito do modelo, um sistema web específico será implementado para automatizar demais tarefas como: a gestão das turmas, criação de atividades e aplicação dos exercícios. Com isso, os estudantes poderão seguir praticando o modelo por meio do smartphone, tablet, notebook ou computador desktop, usufruindo de recursos adicionais como privacidade e estatísticas de acerto. Ao professor, será possível ter uma visão geral da turma, reaproveitar questões e realizar análises comparativas entre resposta espera e resposta fornecida pelo aluno.

\section{Referências}

BEHAR, Patrícia Alejandra. Competência em Educação a distância [recurso eletrônico]/Organizadora , Patrícia Alejandra Behar. - Dados Eletrônicos. - Porto Alegre: Penso, 2013.

BOUCINHA, Rafael Marimon. Aprendizagem do pensamento computacional e Desenvolvimento do raciocínio. Tese de Doutorado, PPGIE, 2017.

BRACKMANN, Christian Puhlmann. Desenvolvimento do pensamento computacional através de atividades desplugadas na educação básica. Tese de Doutorado, PPGIE, 2017.

BRACKMANN, Christian Puhlmann; CAETANO, Saulo V. N.; SILVA, Anita Raquel da; Pensamento Computacional Desplugado: ensino e avaliação na educação primária brasileira. Revista Novas Tecnologias na Educação (RENOTE), v. 17, n. 3, 2019.

DICIO. Disponível em: 〈https://www.dicio.com.br/>. Acesso em: 20 jan 2019.

FONTEYN, m. E., Kuipers, B., \& Grobe, S. J. (1993). A description of think aloud method and protocol analysis. Qualitative Health Research, 3, 430-441.

HENRIQUE, Mychelline Souto; TEDESCO, Patrícia C. de A. R.. Uma Revisão sistemática da Literatura sobre conhecimentos, habilidades, atitudes e competências desejáveis para auxiliar a aprendizagem de programação. In: Congresso Brasileiro de Informática na Educação, 2017, Recife. Anais. Recife: Workshops do VI Congresso Brasileiro de Informática na Educação.

MALHEIROS, Bruno Taranto. Didática geral / Bruno Taranto Malheiros: organização Andrea Ramal - 2. ed. Rio de Janeiro: LTC, 2019.

PAPERT, Seymour M. Mindstorms: Children, Computers and Powerful Ideas. New York: Basic Books, 1980.

PERRENOUD, Philippe. Construir as Competências desde a escola. Trad. Bruno Charles Magne. Porto Alegre: Artes Médicas, 1999.

PIAGET, Jean. Fazer e Compreender. Trad. Cristina L. de P. Leite. São Paulo: Melhoramentos; EDUSP, 1978. 
POLONI, Leonardo; Carine G. Webber. Pensamento computacional no ensino médio: práticas mediadoras utilizando a linguagem Scratch. Revista Novas Tecnologias na Educação (RENOTE), v. 17, n. 3, 2019.

SCHORR, M. C.; BERCHT, M.. Análise longitudinal do desempenho dos estudantes de Ensino Médio e estudantes de nível superior para Algoritmos e Programação. In: Congresso Brasileiro de Informática na Educação, 2018, Fortaleza. Anais. Fortaleza: Workshops do Congresso Brasileiro de Informática na Educação, 2018. v.1. p.550 - 560.

SCRATCH. Disponível em:<https://scratch.mit.edu/about>. Acesso em: 17 jun 2019.

SILVA, T. R.; Medeiros, T. J.; Medeiros, H.; Lopes, R.; Aranha, E. Ensino-aprendizagem de programação: uma revisão sistemática da literatura. Revista Brasileira de Informática na Educação, v. 23, n. 1, p. 182-196, 2015.

SILVA, T. R.; Medeiros, T. J.; Medeiros, H.; Lopes, R.; Aranha, E. Ensino-aprendizagem de programação: uma revisão sistemática da literatura. Revista Brasileira de Informática na Educação, v. 23, n. 1, p. 182-196, 2015.

VALENTE, José Armando. Pensamento Computacional, Letramento Computacional ou Competência Digital? Novos desafios da educação. Revista educação e cultura contemporânea| v. 16, n. 43, p. 147-168, 2019.

WING, J.M. Computational thinking. Communications of the ACM, v.49, n.3, p. 33-35, 2006.

2017. Computational thinking's influence on research and education for all.

Italian Journal of Education Technology, 25(2), 7-14. Doi: 10.1771/2499-4324/922. 